Research Article

\title{
Cost-analysis study of second generation antihistamines used in the treatment of allergic rhinitis in India
}

\author{
Amandeep Singh*, Hitender Kumar
}

Department of Pharmacology, Shri Guru Ram Rai Institute of Medical and Health Sciences, Patel Nagar, Dehradun, Uttarakhand, India

Received: 28 June 2016 Accepted: 05 July 2016

*Correspondence to: Dr. Amandeep Singh, Email: angad.aman@gmail.com

Copyright: (C) the author(s), publisher and licensee Medip Academy. This is an openaccess article distributed under the terms of the Creative Commons Attribution NonCommercial License, which permits unrestricted noncommercial use, distribution, and reproduction in any medium, provided the original work is properly cited.

\begin{abstract}
Background: Second-generation antihistamines (SGAs) are the most commonly used drugs for AR nowadays. The cost of medicines is very important determinant in drug compliance; selection of low cost quality drugs would thus be helpful in improving compliance. Literature search revealed no such study done in India and the current study was thus planned to compare the variation in the cost of different SGAs used for the treatment of allergic rhinitis in India. The study results would help doctors, pharmacists in selecting the least costly options among the available SGAs.

Methods: The costs in Indian rupee (INR) of different generic and branded SGAs available in Indian market were referred from CIMS, drug today and the website www.medindiaguide.com. The dose for each drug was taken as per WHO defined daily dose (DDD) for allergic rhinitis. The highest and lowest price for ten tablets/capsules of each SGA manufactured by different pharmaceutical companies was noted. The percentage cost variation and cost ratio were then calculated for each drug.

Results: Eight oral SGAs with a total of 1050 oral tablets or capsules manufactured by different companies are available for use in AR in India. The highest number of manufacturers were for levocetirizine (483), and lowest for mizolastine (2). Fexofenadine (INR 123.56) was the costliest and levocetirizine the cheapest (INR 2.3) SGA. Maximum variation in price was seen with cetirizine (4300\%). The cost ratio was highest for cetirizine (44), and lowest for mizolastine (1.1). Cetirizine is the only SGA from the National List of Essential Medicines (NLEM) 2015 of India; also the only SGA in the DPCO 2013 list of controlled drugs and formulations.

Conclusions: There is huge variation in the price of same SGA being manufactured by different companies. Between the least expensive and the most expensive cetirizine, there is a huge cost variation of $4300 \%$.
\end{abstract}

Keywords: Second generation antihistamines, Allergic rhinitis, Cost-analysis, Partial pharmacoeconomic study

\section{INTRODUCTION}

Allergic rhinitis (AR) is a very common disease affecting almost 400 million people worldwide. ${ }^{1}$ Classic symptoms of the disease includes rhinorrhea or running nose, sneezing, nasal congestion and nasal itching. Based on the duration of symptoms, AR is classified into intermittent allergic rhinitis (IAR), which is characterized by the occurrence of AR symptoms for less than four days a week or for less than four consecutive weeks, and persistent allergic rhinitis (PER), characterized by the manifestation of AR symptoms for more than four days a week and at least four consecutive weeks per year. ${ }^{2}$ Rhinitis is defined as an inflammation of the lining of the nose and is characterized by nasal symptoms including anterior or posterior rhinorrhoea, sneezing, nasal blockage and/or itching of the nose. Rhinitis is defined as an inflammation of the lining of the nose and is characterized by nasal symptoms including anterior or posterior rhinorrhoea, sneezing, nasal block-age and/or itching of the nose.

Rhinitis is defined as an inflammation of the lining of the nose and is characterized by nasal symptoms including 
anterior or posterior rhinorrhoea, sneezing, nasal blockage and/or itching of the nose. Management of patients with $\mathrm{AR}$ involves avoiding the allergen, if the allergen is known; and/or drug therapy. The drug therapy for patients with AR includes antihistamines, corticosteroids, sympathomimetics and mast cell stabilizers. Among these, $\mathrm{H} 1$ antihistamines especially the second-generation antihistamines (SGAs) are the most commonly used drugs for AR nowadays. SGAs are preferred over first generation antihistamines, as they have quicker onset of action, are highly effective on symptoms such as rhinorrhea, sneezing, and nasal pruritus, and are relatively safe in that they cause less sedation and other side effects of first generation antihistamines., ${ }^{2,3}$

Since the prevalence of AR is very high worldwide, the impact on health economics of the world is very large. The cost of AR in terms of money is even more than that of diseases such as diabetes, hypertension, coronary heart disease and depression. ${ }^{4}$ Although some patients with AR may require SGAs for short duration of 3-5 days, many patients having PER require prolonged or even life-long use of SGAs, putting them under great economic burden. This may lead to non-compliance to drugs and would also affect the disease management and the quality of life of the patient. The cost of medication is one of the most important determinants in compliance to the drugs, especially in developing country like India where most of the people are in the middle-income and low-income group and most do not have health insurance. Selection of low cost quality drugs would thus be helpful in this regard and may improve the patient's compliance to medication.

The Indian market is flooded with large number of drug formulations of various branded and generic antihistamines and the price also varies to a great extent. Drug prices in Indian market are kept under control by the National pharmaceutical pricing authority (NPPA), under the department of pharmaceuticals, Ministry of chemicals and fertilizers, Government of India. NPPA fixes/revises the prices of controlled drugs and formulations and is responsible to implement and enforces the prices and availability of the medicines in the country, as per the drugs prices control order, 2013, an order issued by the Indian government. It fixes the ceiling price of a drug based on essentiality of a drug. The pharmaceutical companies are then free to fix the price for their products equal to or below the ceiling price for that formulation; however, they cannot sell any medicine given in the drugs prices control order (DPCO) list at a cost higher than that fixed under this order. ${ }^{5}$ However, only around $18 \%$ of medicines are under price control. The pharmaceutical companies can market the drugs not included in the DPCO list at a price based on their own calculations. This leads to large discrepancy in the cost of same drug manufactured by different companies in India. ${ }^{6}$
The specialized field of health economics which helps to know the economic burden of disease management to the patient is known as pharmacoeconomics. ${ }^{7}$ Pharmacoeconomics has been defined as the description and analysis of the cost of drug therapy to health care systems and society. ${ }^{8}$ Pharmacoeconomic evaluation is called full economic evaluation when both costs and outcomes are assessed, whereas it is partial economic evaluation when only costs of two or more alternatives are assessed without regard to outcome. 9,10 Partial pharmacoeconomic evaluation will thus help to identify a preferred choice of medicine or treatment among possible alternatives based on the cost.

Literature search revealed no such study done in India which compared the variation in the economic cost of different second generation antihistamines used for the treatment of allergic rhinitis in India. This partial pharmacoeconomic study was thus planned to help create awareness among the doctors, pharmacists, consumers and other stakeholders' regarding the range of price differences between the various generic and non-generic brands of the same SGA's being manufactured by different companies in India and thus may prove beneficial in decreasing the prescription costs.

\section{METHODS}

The costs of different generic and branded SGAs available in Indian market were referred from drug today October-December 2015, current index of medical specialties (CIMS) January-April 2016 and the website www.medguideindia.com. ${ }^{11-13}$ The cost of drugs in Indian rupee (INR) per ten tablets or capsules with same strength and dose of each drug and if available, cost of one injection with same strength and dose were included in the study. The dose for each drug was taken as per WHO defined daily dose (DDD), from WHO anatomical, therapeutic and chemical (ATC) classification system for allergic rhinitis. According to WHO, "DDD is the assumed average maintenance dose per day for a drug used for its main indication in adults". ${ }^{14}$

The highest and lowest price of each SGA manufactured by different pharmaceutical companies was noted. The percentage cost variation and cost ratio were then calculated for each drug. The percentage variation in the cost of the drugs was calculated using the following formula:

Percentage cost variation $=($ Most expensive formulation of the same SGA-Least expensive formulation of the same SGA)/(Least expensive formulation of the same SGA) $x 100 .^{15,16}$

\section{Cost ratio formula}

Cost ratio=Most expensive formulation of the same SGA/Least expensive formulation of the same SGA. ${ }^{17}$ It helps in determining how many times the most expensive 
formulation is costlier than the least expensive formulation of the same drug.

\section{Exclusion criteria}

Fixed dose combinations (FDC's) with first generation anti-histamines or with drugs other than SGAs, drug formulations of varying strength and drugs with no cost information. The study did not involve intervention or interactions with the patient or subjects and ethics committee approval was thus not required for this study.

\section{Statistical analysis}

The data were entered in Microsoft excel 2010 software and percentage cost variation and cost ratio were calculated using this software.

\section{RESULTS}

A total of eight oral SGAs used in allergic rhinitis are available in the Indian market, and a total of 1050 oral tablets or capsules manufactured by different companies were identified for all the SGAs.

Table 1: Cost analysis of second generation antihistamines available in Indian market.

\begin{tabular}{|llllll|l|}
\hline Drug Name & $\begin{array}{l}\text { DDD } \\
\text { (WHO) } \\
(\mathbf{m g})\end{array}$ & $\begin{array}{l}\text { No. of } \\
\text { manufacturing } \\
\text { companies }\end{array}$ & $\begin{array}{l}\text { Least expensive } \\
\text { (INR)* }\end{array}$ & $\begin{array}{l}\text { Most expensive } \\
\text { (INR)* }\end{array}$ & $\begin{array}{l}\text { Cost } \\
\text { ratio }\end{array}$ & $\begin{array}{l}\text { Cost } \\
\text { variation } \\
(\%)\end{array}$ \\
\hline Cetirizine hydrochloride & 10 & 344 & 2.5 & 110 & 44 & 4300 \\
\hline Levocetirizine & 5 & 483 & 2.3 & 80 & 34.8 & 3378 \\
\hline Loratadine & 10 & 76 & 19 & 83 & 4.4 & 337 \\
\hline Desloratadine & 5 & 37 & 19.9 & 64 & 3.2 & 222 \\
\hline Fexofenadine hydrochloride & 120 & 86 & 25 & 123.56 & 4.9 & 394 \\
\hline Ebastine & 10 & 6 & 40 & 64.5 & 1.6 & 61 \\
\hline Rupatadine & 10 & 16 & 45 & 105 & 2.3 & 133 \\
\hline Mizolastine & 10 & 2 & 54.12 & 61.5 & 1.1 & 14 \\
\hline
\end{tabular}

*Cost per ten tablets or capsules; INR: Indian rupee

Largest number of manufacturers are for levocetirizine (483), followed by cetirizine (344) and lowest for mizolastine (2). No oral formulation of azelastine is available in India and only nasal spray and eye drops are available, so it was not included in the study. No injectable SGA is available in Indian market and so could not be included in the study. The cost per ten tablets or capsules was highest for fexofenadine hydrochloride (INR 123.56) and lowest for levocetirizine (INR 2.3) (Table 1). For the same drug, the largest variation in price was seen with cetirizine $(4300 \%)$, followed by levocetirizine $(3378 \%)$ and the minimum with mizolastine $(14 \%)$. The cost variation between the cheapest (levocetirizine; INR 2.3) and the costliest SGA (fexofenadine hydrochloride; INR 123.56) was $5272 \%$. The cost ratio ranged from 1.1 for mizolastine to 44 for cetirizine. The cost ratio for the most expensive SGA (fexofenadine) and least expensive SGA (levocetirizine) was 53.7.

Only one fixed dose combination (FDC) of SGAs, an FDC of cetirizine $5 \mathrm{mg}$ and levocetirizine $5 \mathrm{mg}$ is available in Indian market, at a price of INR 28 for 10 tablets. Cetirizine is the only SGA from the National List of Essential Medicines (NLEM) 2015 of India, and only one drug loratadine is from the WHO Model List of Essential Medicines, $19^{\text {th }}$ edition, 2015 (WHO-EML 2015) ${ }^{18,19}$ Only one SGA cetirizine is in the DPCO 2013 list of controlled drugs and formulations. ${ }^{5}$

\section{DISCUSSION}

In this study, huge variation was found in the cost of different generic and branded preparations for the same drug $(4300 \%$ for cetirizine; INR 2.5 to INR 110$)$ and between different SGAs (5272\%; INR 2.3 for levocetirizine to INR 123.56 for fexofenadine). Most expensive cetirizine was 44 times costlier than the least expensive cetirizine, levocetirizine 34.8 times costlier than the least expensive levocetirizine, and the costlier mizolastine was 1.1 times the lower priced one. No similar study for SGAs could be found in India; however studies with other drugs for other conditions reveal similar findings of huge variation in price. ${ }^{20,21}$ For cetirizine and levocetirizine, the cost variation were much more than seen in a number of similar studies with other drugs. ${ }^{22-24}$

As per WHO, $60 \%$ of total health spending in India is out of pocket. ${ }^{25}$ Drugs account for $72 \%$ of the total private out-of-pocket expenditure. ${ }^{26}$ Over 63 million people in India are faced with poverty every year due to health care costs alone. This is associated with very low public spending on health in India at $4.1 \%$ of GDP, as compared to minimum $5-6 \%$ requirement. ${ }^{27}$ This, despite India being the third largest producer of pharmaceutical products in terms of volume in the world, with large number of companies manufacturing each drug. Providing quality medicines available to the people at low cost will be an effective way of making healthcare affordable. 
Cost of drugs is an important determinant of compliance to treatment by the patients. In a study by Boston consulting group, $17 \%$ of patients reported noncompliance to drugs due to the high cost of medication. ${ }^{28}$ In another study, the most common reasons for noncompliance were related to the cost of medication: $55.5 \%$ of the patients thought that the drug would cost too much, and $20.2 \%$ said that the medicines were not covered by insurance. $^{29}$

Government policies play a very important role in keeping the cost of drugs low. India currently has less than $1 / 5$ th of its medicines under price control; the government should thus bring more drugs under the ambit of price control to ensure affordability. ${ }^{6}$ A good example is Egypt, which has brought all its medicines under price control. ${ }^{30}$ Although the government has helped to keep the VAT on medicines at a uniform rate of $4 \%$ throughout India, abolition of VAT and other taxes on essential medicines can be considered, as in Tajikistan. ${ }^{31}$ Government should introduce low-cost insurance schemes to increase the economic affordability and thus compliance to therapy.

The Indian government and its state governments are trying to provide low cost drugs to people by establishing centers like Jan aushadhi, niramaya arvi and locost. ${ }^{32-34}$ Indian government has recently started 293 'Jan aushadhi' generic medicine stores to provide low-cost quality medicines to people of India, although the number is quiet less in comparison to the India's large population of 1.2 billion. ${ }^{32}$ Similar generic life line drug stores have also been set-up by the Rajasthan government. ${ }^{35}$ Niramaya arvi is another initiative, taken up by the administration, doctors and chemists of Wardha district to provide effective medicines at low-cost to the patients, by making the doctors, chemists and consumers aware regarding the massive price difference between different brands for the same drug formulation. ${ }^{33}$ A Baroda-based voluntary organization, Locost is another organization that manufactures quality medicines at their own manufacturing unit at very low prices and helps provide quality low-cost drugs to the rural and urban poor. Currently, they make more than 60 essential medicines in 80 formulations. $^{34}$

In India the large number of different preparations for the same drug helps create market competition and thus to a great extent helps in keeping the cost of the drugs on the lower side. The DPCO, 2013 list of price-controlled drugs includes only one SGA cetirizine. The drugs not on the DPCO list are outside the purview of NPPA and manufacturers are free to price their drugs as per their choice. However, even though levocetirizine is not on the DPCO 2013 list, it is available at lower price (INR 2.3 per ten tablets) than that of cetirizine whose cheapest version is available at INR 2.5 per ten tablets. This is probably made possible by market competition as there are around 490 different companies manufacturing levocetirizine. The drug mizolastine has just two manufacturers, and the cheapest drug was available at much higher price of INR 54.12, probably due to minimal market competition. Thus, competition in the pharmaceutical market is an important factor in keeping the cost of drugs low, as is revealed in our study and in a study by Karve AV et al. ${ }^{23}$

The cheapest cetirizine in India is for INR 0.25 per tablet/capsule and the costliest for INR 11 per tablet/capsule. Thus, a patient on the cheapest cetirizine would be saving $97.97 \%$ on his bill (an amount of INR 10.75 per dose), and a huge amount of INR 3923.75 per year. The SGAs are quiet similar in terms of their efficacy, although may vary in terms of their adverse effects.36 A patient on the cheapest SGA (levocetirine; INR 0.23 per dose) available in Indian market in comparison to the costliest SGA (fexofenadine; INR 12.36 per dose) would be saving an amount of INR 12.13 per dose and a huge amount of INR 4427 per year. Physicians should thus prescribe the low cost drugs and should not be influenced by pharmaceutical industries. Free lunches, free conferences, free holiday trips, gifts and other unfair practices used by pharmaceutical industries to influence prescribing should be strictly discouraged. Medical council of India is taking an initiative in this regard. ${ }^{37}$

The role of pharmacist is also very important in influencing the cost at which drugs are available to the patients. It has been seen that unbranded generics, although cheaper are rarely sold in private pharmacies due to lower profit margin. Also, the margin by the companies to pharmacists varies to a great extent, with the drug giving higher margin to the pharmacist being preferred. Moreover, many of the patients with allergic rhinitis buy these drugs over-the-counter and in many cases the consumer is left with no choice but has to buy the drugs as per the pharmacist's selection.

The main aim of policy makers to make healthcare affordable should be easy accessibility of consumers to quality, low-priced drugs to reduce the cost of treatment, which in turn would help increase the compliance and quality of life of patients. This can be made possible by further increasing the competition in the pharmaceutical market, more stringent price control especially on the essential drugs, prescription of generic drugs, low cost insurance schemes by government, proactive role by the state governments, making doctors, pharmacists and consumers aware especially through similar studies, the media and various social campaigns like 'Jago grahak jago' regarding the massive price difference between different brands.

\section{CONCLUSION}

There is huge variation in price of a particular second generation antihistamine being manufactured by different companies and also between the different SGAs available in the Indian market. Between the least expensive and the most expensive cetirizine, there is a huge cost variation of 
$4300 \%$. Also, levocetirizine at the cost of INR 2.3 per ten tablets was the least expensive SGA and costliest was fexofenadine at INR 123.56 per ten tablets, a huge cost variation of $5272 \%$.

\section{Funding: No funding sources}

Conflict of interest: None declared

Ethical approval: Not required

\section{REFERENCES}

1. WAO White Book on Allergy 2011-2012: Executive Summary. Available at: http:// www. worldallergy. org /publications/ wao_white_book.pdf. Accessed on 21 April 2016.

2. Bousquet J, Khaltaev N, Cruz AA, Denburg J, Fokkens WJ. Allergic rhinitis and its impact on asthma (ARIA) 2008 update (in collaboration with the World Health Organization. Allergy. 2008;63(86):8-160.

3. Hansen J, Klimek L, Hormann K. Pharmacological management of allergic rhinitis in the elderly: safety issues with oral antihistamines. Drugs Aging. 2005;22:289-96.

4. Ramirez JF, Pavon RG, Juarez MLL, Teran LM. Allergic Rhinitis. J Aller Ther. 2012;5:6.

5. Drugs Prices Control Order. 2013. Available at: http:// www. nppaindia. nic. in/ DPCO 2013.pdf. Accessed on 9 May 2016.

6. Srinivasan S, Srikrishna T, Aisola M. Pharma price control policy: unrealistic and unfair. Economic Political Weekly. 2014;49(34):13-5.

7. Haycox A, Boland A, Walley T. Basics of economics, health economics and pharmacoeconomics. In: Walley $\mathrm{T}$, Haycox $\mathrm{A}$, Boland A, eds. Pharmacoeconomics. Edinburgh: Churchill Livingstone;2004:1-16.

8. Townsend RH. Post marketing drug research and development. Drug Intell Clin Pharm. 1987;21:1346.

9. Trask LS. Pharmacoeconomics: principles, methods, and applications. In: Dipiro JT, Talbert RL, Yee GC, Matzke GR, Wells BG, Posey L, eds. Pharmacotherapy: A Pathophysiologic Approach. $8^{\text {th }}$ ed. New York: McGraw-Hill Global Education Holdings;2011. Available at: http://accesspharmacy.mhmedical.com/content.aspx ?bookid $=462 \&$ Sectionid $=41100767$. Accessed on 26 April 2016.

10. Kulkarni U, Dalvi K, Moghe VV, Deshmukh YA. Pharmacoeconomics: An emerging branch in heath science for decision making. Afr $\mathbf{J}$ Pharm Pharmacol. 2009;3(8):362-8.

11. Current index of medical specialities. UBM Medica India Private Limited, Bangalore. 2016:132;479-87.

12. Mishra L. Drug today: Ready reckoner of current medical formulations. Lorina Publications (India) Inc., New Delhi. Oct-Dec 2015.
13. Defined daily dose. Available at http://www.whocc.no/ddd/definition_and_general_c onsidera/. Accessed on 11 Dec 2015.

14. Comparison: Percent Difference. Available at http://www.oracle.com/webfolder/technetwork/dataquality/edqhelp/Content/processor_library/matching/ comparisons/percent_difference.htm. Accessed on 19 April 2016.

15. Shankar PR, Subish P, Mishra P, Lalit M. Ambiguous pricing of Nepalese medicines. J Institute Med. 2006;28:35-8.

16. Lal A, Sharma ML. A calm look at the cost of drugs in psychiatric practice. Indian $\mathbf{J}$ Psychiat. 1992,34(1),18-20.

17. WHO Model List of Essential Medicines. Available at http:// www. who. int/ medicines/ publications/ essentialmedicines/en/index.html. Accessed on 13 March 2016.

18. National List of Essential Medicines of India, 2015. Available at: http: //cdsco.nic.in/ WriteReadData /NLEM-2015/NLEM,\%202015.pdf. Accessed on 13 March 2016.

19. Date AP, Mahajan HM, Dashputra AV, Bhosale RR. Study of variation in price of various antidiabetic drugs available in Indian market. Int $\mathbf{J}$ Basic Clin Pharmacol. 2015;4:36-40.

20. Wagle L, Kumaraswammy M, Kempegowda MB. Cost variation study of antiepileptic drugs available in India. Asian J Pharm Clin Res. 2016;9(2):64-8.

21. Akila L, Rani J. Cost analysis of different brands of antianginal drugs available in India. Int J Basic Clin Pharmacol. 2015;4(5):860-3.

22. Karve AV, Chattar KB. Cost analysis study of oral antihypertensive agents available in Indian market. Int J Basic Clin Pharmacol. 2014;3:479-83.

23. Phatak A, Hotwani J, Deshmukh K, Panchal S, Naik M. Cost analysis of long established and newer oral antiepileptic drugs available in the Indian market. Int J Med Res Health Sci. 2015;4(4):744-8.

24. World health statistics 2012. Available at http://apps.who.int/iris/bitstream/10665/44844/1/978 9241564441_eng.pdf?ua=1. Accessed on 27 March 2016.

25. Kumar AKS, Chen LC, Choudhury M, Ganju S, Mahajan V, Sinha A, et al. Financing health care for all: challenges and opportunities. Lancet. 2011;377:668-79.

26. Draft National Health Policy. Available at: http://www.thehinducentre.com/multimedia/archive/ 02263/Draft_National_Hea_2263179a.pdf. Accessed on 28 April 2016.

27. Boston Consulting Group. The hidden epidemic: finding a cure for unfilled prescriptions and missed doses. 2003. Available at http:// www.bcg.com /documents/file14265.pdf. Accessed on 10 May 2016.

28. Kennedy J, Tuleu I, Mackay K. Unfilled prescriptions of medicare beneficiaries: prevalence, reasons, and types of medicines prescribed. J Manag Care Pharm. 2008;14(6):553-60. 
29. Srinivasan S, Bhargava A. Impoverishing the poor: pharmaceuticals and drug pricing in India. Low Cost Standard Therapeutics (LOCOST). Vadodara/Bilaspur,India.2004. Available at http: //www. Jssbilaspur .org /wordpress /wp-content /uploads /2015 /10 /Impoverishing -the -poorPharmaceuticals-and-drug-pricing-in-India.pdf. Accessed on 27 March 2016.

30. World Health Organization and Health Action International. Measuring medicine prices, availability, affordability and price components. 2008. Available at: http: //www.who.int /medicines /areas /access/ OMS_Medicine_prices.pdf. Accessed on 27 March 2016.

31. Jan aushadhi. Available at: http:// janaushadhi.gov.in /about_jan_aushadhi.html. Accessed on 17 March 2016.
32. Niramaya Arvi. Available at https:// niramayaarvi. wordpress.com. Accessed on 17 March 2016.

33. Low cost standard therapeutics (LOCOST). Available at: http:// www. locostindia. com/. Accessed 17 March 2016.

34. Life Line drug store. Available at: http://www.rmsc.nic.in/llds.html. Accessed 11 June 2016.

35. Adis international limited. Second-generation antihistamines have similar efficacy in allergic rhinitis, but their tolerability and metabolism differ. Drug Ther Perspect. 2007;23:17-9.

Cite this article as: Singh $\mathrm{A}$, Kumar H. Costanalysis study of second generation antihistamines used in the treatment of allergic rhinitis in India. Int J Basic Clin Pharmacol 2016;5:1228-33. 